\title{
Dynamics of Cooperative Learning- an EFL perspective
}

\author{
${ }^{1}$ Dr. Bh. V. N. Lakshmi, ${ }^{2}$ S. A. Mangatayaru \\ ${ }^{1}$ Professor of English, Shri Vishnu Engg. College for Women, Bhimavaram, A.P., India \\ ${ }^{2}$ Asst. Professor of English, Shri Vishnu Engg.College for Women, Bhimavaram, A.P., India.
}

\begin{abstract}
In the present day competitive world, 'cooperation' became a buzz word for the collective progress of humanity in all aspects. The advancement of science and technology on one hand changed the contours of knowledge demanding specialization in chosen field, compartmentalization in life and competition in work environs. Initially cooperation is an attribute that enables a community to live or work together. Gradually it permeated into teaching-learning process ensuring innovation, interaction and improvement in student-centric teaching approach. Endorsing the benefits of cooperative learning we experimented with cooperative learning techniques implementing them to teach English language to the undergraduate engineering students in the semiurban locale. The observations and results impacted our teaching-learning process, increasing the scope of exploring the dynamics of Cooperative Learning.
\end{abstract}

\section{Introduction}

In the present day competitive world, 'cooperation' became a buzz word for the collective progress of humanity in all aspects. On one hand the advancement of science and technology has changed the contours of knowledge demanding specialization in chosen field, compartmentalization in life and competition in work environs. This invariably desiccated the human sensitivity inviting stress and confusion. On the other hand it has necessitated team work and cooperative learning reiterating the fact that 'man is a social being.' Initially cooperation was an attribute that enabled a community to live or work together. Gradually it permeated into teaching-learning process ensuring innovation, interaction and improvement in student-centric teaching approach.

Down the ages, thinkers and social scientists have played a key role in welcoming changes in the education system keeping in mind the future prospects and collective progress of a Nation. With an intention to find out a true education system by experience and experiment, M K Gandhi established the Phoenix settlement and the Tolstoy Farm in South Africa emphasizing the virtues of the simple life of love, labour, and the dignity of human beings. Ascendency of cooperative learning in $21^{\text {st }}$ century can be clearly understood with an insightful glimpse at Alvin Toffler's book The Third Wave. Toffler sums up human history in three waves of technological innovation. The first wave, reaching back to the dawn of human civilization, is agriculture. Here the educational focus is on handicrafts. The second, starting about 1700, is industry. It enhanced literacy with teacher-centered learning. The third, beginning in the 1950s, is computers and information technology. Young people started absorbing new technology faster than the diehard older people. Thus, in the skill-oriented modern education cooperative learning plays a key role and no wonder today the word 'illcomputerate' hasreplaced 'illiterate.'

According to academic scientists 'Cooperative Learning' is an accepted and often the preferred instructional procedure at all levels of education. Emphasizing the benefits of cooperative learning Colorin Colorado states that "Cooperative Learning has been proven to be effective for all types of students, including academically gifted, mainstream students and English language learners (ELLs) because it promotes learning and fosters respect and friendship among diverse groups of students." Endorsing the same we experimented with cooperative learning techniques implementing them to teach English language to the undergraduate engineering students in the semi-urban locale. The observations and results impacted our teaching-learning process, increasing the scope of exploring the dynamics of Cooperative Learning.

\section{Dynamics of Cooperative Learning}

Insightful comprehension of the dynamics of Cooperative Learning is essential for the effective pedagogical implications. Following the lessons of Richard Felder, Johnson \& Johnson model of Cooperative Learning is taken into consideration for exploration and experimentation in EFL classes in a technological institution where employability is the educational outcome. According to Johnson \& Johnson, Cooperative Learning is "the instructional use of small groups so that students work together to maximize their own and each other's learning." Forming the groups in a classroom and instructing them to work togetherdoes not mean they will cooperate effectively. To be cooperative and to reach the full potential of the group, five essential elements 
need to be carefully structured into the situation: positive interdependence, individual and group accountability, promotive interaction, appropriate use of social skills, and group processing (Johnson \& Johnson, 1989, 2005). This acts almost as a blueprint facilitating the teachers to structure and tailor cooperative learning lessons to unique instructional needs, employability, curricula and students.

\subsection{Benefits of Cooperative Learning in terms of employability}

\subsubsection{Assists the students in becoming industry-ready}

The emerging specializations are calling for a holistic approach in all walks of life. Simultaneously technological might is isolating the individuals and it is not an exaggeration if we say that man is synonymous to a machine today. In most of the academic institutions students are getting glued to their mobiles, laptops or ipads. This environment might enhance their technical knowledge but certainly distance them from interpersonal and intrapersonal skills. This is the area where cooperative learning enables fine balance with no place for mismatch between academic objectives and industry requirements.

\subsubsection{Allows wider sharing that enhances employability}

In the process of executing the given group task effectively students behave more selfless bysharing information. In the case of individual task students particularly girls tend to become more possessive and information blockage occurs. Whereas in Cooperative Groups, the meritorious gives subject knowledge, socialmedia proactive ones gather the required test strategies and other prerequisites of various industries from the blogs and other online resources, average students invite revision and the industrious brings in hardwork. This certainly enhances the employability of not one but all in the group.

\subsubsection{Instills sportiveness and promotes self esteem.}

Knowledge diversity in a group might initially delay the cooperation but under the effective guidance of the instructor members in the group can cross out their hesitations. They endure arguments, discussions and experience disapprovals and endorsements. Yet they learn to move forward together. Each one is enforced to play both active and dormant roles in cooperative groups. Adaptability in the group incurs sportiveness and enriches confidence.

\subsubsection{Increases learners' cognitive ability}

Working independently for a long time might invite procrastination. On the contrary cooperative learning keeps every member in the group not only active but also responsible. It is easier for any student to learn from friends rather than a teacher or a book. Exchanging doubts and solutions enhance the cognitive ability of the students.

\subsubsection{Provides edutainment}

With cooperative learning, education is no more a burden but an edutainment. It is entertaining, generates creative ideas and encourages collective progress through knowledge sharing. Cooperative learning advocates the truth that knowledge is no one's property.

\subsection{Participants}

\section{Pedagogical implications}

The participants were third year engineering students who were supposed to be groomed in their communication skills, verbal reasoning and analytical writing skills to get industry-ready by the time they would complete their undergraduate engineering course.

\subsection{Targeted skills}

Catering to the needs of the present day industrial world, students were trained in Group Discussions, Just A Minute (JAM) talks, Interview skills, Vocabulary, Grammar, Reading Comprehension skills, Analytical writing and Presentation skills.

\subsection{Formation of groups}

The whole class was given clear instruction about cooperative learning. After creating required excitement, a common test was conducted covering vocabulary and basic grammar in the class of 60 students. According to the test marks the whole class was formed into 12 groups with 5 students in each group. Every group had excellent, good, average and below average students. These groups were not fixed groups and were subjected to change with varying activities. 


\subsection{Cooperative Learning Structures}

Trained directly by Richard Felder on "Effective Teaching" in a workshop, the following three cooperative learning structures were implemented in theclassroom for third year engineering students.

3.4.1Think-Pair-Share (TPS): Lyman in 1978 developed this cooperative learning strategy and described it as "a multi-mode discussion cycle in which students listen to a question or presentation, have time to think individually, talk with each other in pairs, and finally share responses with the larger group" (McTighe and Lyman, 1988: 243).

Throughout the semester every week one class was scheduled for news paper work targeting vocabulary, tenses, articles, prepositions and sentence structures. All groups followed same English news paper. The instructor could make the groups work by allowing them to identify vocabulary/articles/prepositions from a particular news article. After giving sufficient explanation, the groups were allowed to write five sentences on their own using vocabulary/articles/prepositions. Each student needs to write one sentence after discussing with the group. Sometimes they were instructed to write a story and all the groups were allowed to give critical appreciation of the article. Utilizing the facility of Vishnu TV academy in the institution, the students in pairs were scheduled every day to consolidate the information in the news paper and read it in a news bulletin after college hours and it was telecasted to all the TVs within the campus. This invariably gave the students an edge over others in HR interview round as they got acquainted with current affairs and could speak on any topic effortlessly.

\subsubsection{Jigsaw}

As per the opinion of Aronson and Slavin the jigsaw models have been developed for narrative material where the goal is to learn concepts rather than skills. In jigsaw students leave their original group and form an "expert group", in which all students analyze the same piece of information and after qualitative critical appreciation, decide how best to teach it to their peers in the original group. With a concrete idea they go back to their original groups and teach their portion of the lesson to others in the group.

Since it was felt that this model was very effective to train the students in group discussions and presentations, it was implemented in the class. In each group, students were given 1, 2, 3, 4, 5 numbers. The instructor took a topic, for instance, Solar Sails and divided it into introduction, Physical principles, Applications, Projects completed and Limitations. Each part was assigned to the five students in a group respectively. The assignment was same to all 12 groups. After giving enough time for research and data collection on the given topic, number 1student from all groups formed into an expert group, similarly all $2 \mathrm{~s}, 3 \mathrm{~s}$, $4 \mathrm{~s}$ and $5 \mathrm{~s}$ formed as separate expert groups. This increased the number of students to 12 in each group and they brain stormed the assigned portion of the topic extensively. With widened scope of information and understanding they went back to their original group and educate theother members in the group. This enabled individual participation and effective sharing of information.

Bridging engineering knowledge and communication ability, the groups were encouraged to work on interesting technological aspectslike Digital Jewelry, Swarm technology, Memory metals, Magnetic levitation, Stereo-lithography and Bionic Body parts. After accomplishing group learning they were encouraged to film their presentation in Vishnu TV academy established in the institution. Those presentations are viewed in the English language laboratory by the whole class and the instructor gave feedback on each student's presentation at the end. The best presentation group and the best presenter were rewarded appropriately.

\subsubsection{Peer-Led Team Learning (PLTL)}

The Peer-Led Team Learning (PLTL) can be defined as a model that utilizes Peer-Led group activities among students to enhance student understanding of any given topic. PLTL provides an active learning environment that creates leadership roles for undergraduates, and engages faculty in a creative and revolutionary new method of teaching.

Endorsing the effectiveness of PLTL, it was implemented to train students in learning to answer Reading comprehension and Analytical writing questions and how to face interviews. It was not practically feasible for an instructor to train effectively each and every student in a class of 60. So the instructor selected 10 students whose cognitive skills were above average and instructions were given on the above mentioned aspects. Each student was given utmost attention while instructing and clarification was given for every possible doubt. These students in turn train the others in the class and together practiced and prepared themselves for their employability. They organized mock interviews through role play and took free online TOEFL/GRE tests and analyzed comparing their answers. 


\section{Observations}

Despite a few hiccups, the implementation of Cooperative learning gave positive results boosting the morale of EFL faculty in technological institutions in restructuring their lesson plans in association with institute and industry objectives and outcomes. A brief glimpse of the positive results of Cooperative learning is given below.

- It provided an active learning experience for students.

- It was evident that students performed better in campus recruitment compared to the previous batch students.

- It facilitated to bring forth positive changes in traditional teaching-learning process.

- A healthy interactive environment established among the peers and this impacted overall academic system in women's engineering college.

- News paper reading became a habit and changed their informal discussions from TV serials to national and international socio-political aspects and technological issues.

- There was a marked change in their thinking and most of them determined to be true professionals.

- Shedding off their possessiveness and jealousy most of the girl students learned sociability and habituated to share and progress together.

- There was improvement in the number of students getting employed.

- The scope of knowledge widened due to sharing between heterogeneous groups.

- Self-esteem increased in average and below average students.

- $\quad$ Fine tuned leadership qualities in the students who have the ability to lead.

- Quelled the superiority/inferiority complex among the peers.

- Students became proactive and absenteeism reduced.

- It reduced stress on the part of the instructor and provided enough space for careful planning.

- It created a leadership role for undergraduates.

- It engaged faculty in a creative dimension of instruction by offering timely assistance to the student groups, by using various techniques for problem solving and also by providing guidance and encouragement.

- It allowed optimal utility of the resources available in the institution and increased the scope of employability of women engineers.

- It enabled students to be respectful of each other and without any critical intention disagree with other person's position and ideas and understand the differences objectively.

- $\quad$ Focused on reaching the best outcome, not on winning.

Improvement in reading skills, analytical writing, speaking skills and campus recruitment is depicted in the graph below:

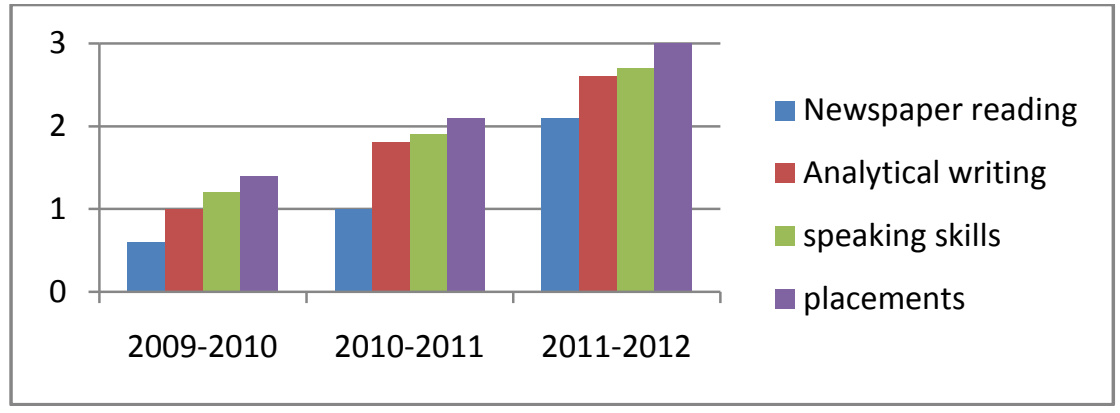

\section{Conclusion}

"Example is better than a precept," advocating this fact English faculty in Shri Vishnu Engineering College for Women, Bhimavaram, Andhra Pradesh took a collaborative initiation of experimenting the implementation of cooperative learning with one of its faculty being directly trained by Richard Felder in 2010 FLI workshop on "Effective Teaching." Sharing that experience the department of English made a collective effort and took three Cooperative Learning strategies for experimentation keeping in view the objectives and outcomes. Yet the whole process was not free from difficulties. The instructor needs to be more insightful in tracing the peer rivalry and direct them towards holistic approach. In the ongoing process all initial hiccups gradually erased as there is a shift from teacher-centered learning to student-centric learning. In a democratic class room Cooperative Learning plays a key role but in meritocratic class room its survival is doubtful. Everystudent wants to excel in his/her chosen field but ultimately merit should prevail or else the whole system ends up in mediocrity. The instructor should guide the meritorious few and they in turn should teach the others taking it as a social responsibility. 


\section{References}

[1]. Johnson D. W., \& Johnson, R. Cooperation and competition: Theory and research. Edina, MN: interaction Book Company. 1989.

[2]. Hamilton. 'Steve Jobs and the third wave: 'Jobs' reminds us of the limits of techno-determinism.' Viewed on 16 Oct 2013. Retrieved from http://www.breitbart.com/Big- Hollywood/2013/08/15/Jobs-Review-Reminds-Us-of-the-Limits-of-TechnoDeterminism

[3]. Lyman, F. "The responsive classroom discussion." In Anderson, A. S. (Ed.), Mainstreaming Digest, College Park, MD: University of Maryland College of Education. 1981.

[4]. Millis, B. J., and Cottell, P. G., Jr. Cooperative learning for higher education faculty, American Council on Education, Series on Higher Education. The Oryx Press, Phoenix, AZ. 1998.

[5]. Johnson, D. W., Johnson, R. T., and Smith, K. A. Active learning: Cooperation in the collegeclassroom. Edina, MN: Interaction Book Company. 1998.

[6]. Felder, R. M.; Brent, R. 'Cooperative Learning,' Viewed on 18 Oct. 2013. Retrieved from http://uaonline.ua.pt/upload/med/med_664.pdf

[7]. Colorado, C. 'Cooperative Learning Strategies.' Viewed on 14 Oct 2013. Retrieved from http://www.colorincolorado.org/educators/content/cooperative/ 